Article

\title{
In Situ Water Quality Improvement Mechanism (Nitrogen Removal) by Water-Lifting Aerators in a Drinking Water Reservoir
}

\author{
Zizhen Zhou ${ }^{1,2,3}$, Tinglin Huang ${ }^{2,3, *}$, Weijin Gong ${ }^{1}$, Yang $\mathrm{Li}^{1,2,3}$, Yue Liu ${ }^{1}$, Fuwang Zhao ${ }^{1}$, \\ Yanyan Dou ${ }^{1}$, Shilei Zhou ${ }^{2,3}$ and Weixing Ma ${ }^{2,3}$ \\ 1 School of Energy and Environment, Zhongyuan University of Technology, No. 41 Zhongyuan Road (M), \\ Zhengzhou 450007, China; 6623@zut.edu.cn (Z.Z.); gwjgln@163.com (W.G.); ly_xauat@163.com (Y.L.); \\ yue5757@sina.com (Y.L.); zhaofuwangzfw@163.com (F.Z.); doudouwxq@163.com (Y.D.) \\ 2 Key Laboratory of Northwest Water Resource, Environment and Ecology, MOE, Xi'an University of \\ Architecture and Technology, Xi'an 710055, China; zhouzizhen001@sina.com (S.Z.); \\ hs_weixing@163.com(W.M.) \\ 3 Shaanxi Key Laboratory of Environmental Engineering, Xi'an University of Architecture and Technology, \\ Xi'an 710055, China \\ * Correspondence: huangtinglin@xauat.edu.cn; Tel.: +86-29-8220-1038; Fax: +86-29-8220-2729
}

Received: 18 July 2018; Accepted: 6 August 2018; Published: 8 August 2018

\begin{abstract}
A field scale experiment was performed to explore the nitrogen removal performance of the water and surface sediment in a deep canyon-shaped drinking water reservoir by operating WLAs (water-lifting aerators). Nitrogen removal performance was achieved by increasing the densities and N-removal genes (nirK and nirS) of indigenous aerobic denitrifiers. After the operation of WLAs, the total nitrogen removal rate reached $29.1 \pm 0.8 \%$ in the enhanced area. Ammonia and nitrate concentrations were reduced by $72.5 \pm 2.5 \%$ and $40.5 \pm 2.1 \%$, respectively. No nitrite accumulation was observed. Biolog results showed improvement of carbon metabolism and carbon source utilization of microbes in the enhanced area. Miseq high-throughput sequencing indicated that the denitrifying bacteria percentage was also higher in the enhanced area than that in the control area. Microbial communities had changed between the enhanced and control areas. Thus, nitrogen removal through enhanced indigenous aerobic denitrifiers by the operation of WLAs was feasible and successful at the field scale.
\end{abstract}

Keywords: aerobic denitrification; field scale experiment; nitrogen removal; nirS and nirK; microbial community variation

\section{Introduction}

Nowadays, more and more reservoirs are being used as water sources by large cities. Excessive nitrogen in these reservoirs results in poor water quality with a severe impact on aquatic ecosystems, and it has given rise to health considerations in humans and in livestock $[1,2]$. Thus, nitrogen removal from drinking water reservoirs is a critical problem.

Physical, chemical, and biological technologies have been used for nitrogen removal, however, physical and chemical methods incur high costs and are unable to remove nitrogen completely. Bioremediation (biological technology) refers to the use of microorganisms to eliminate or reduce the concentration of hazardous wastes at a contaminated site. Bioremediation has the advantage of no second-pollution or residues [3]. Many researchers have achieved satisfying results for bioremediation in water quality improvement using N-functional bacteria for phosphate, nitrogen, and chemical oxygen demands [4-6]. However, bioremediation through bioaugmentation may result in 
environmental safety problems by changing the composition of indigenous microbial communities [3]. Therefore, $\mathrm{N}$-functional bacteria are rarely reported for use in purifying surface water ecosystems, especially drinking water reservoirs.

In the traditional opinion, bioremediation for nitrogen removal involves autotrophic nitrification and heterotrophic denitrification. Nitrification is achieved under aerobic conditions, whereas denitrification requires anaerobic and anoxic conditions through a sequence of intermediates (nitrate, nitrite, nitric oxide, and nitrous oxide), resulting in nitrogen gas formation $[7,8]$. Due to inhibition by dissolved oxygen, the traditional process of biological nitrogen removal can seldom be used in reservoirs. However, aerobic denitrifying bacteria that simultaneously utilize oxygen and nitrate as electron acceptors were reported in the early 1980s and provided novel insights in bioremediation for drinking water reservoirs [7,9]. Compared with traditional denitrification, aerobic denitrification has attractive advantages: nitrification and denitrification can exist in one system and denitrification can supply sufficient alkalinity to partially balance the acidity of nitrification $[10,11]$. The isolated aerobic denitrifying bacteria with satisfying nitrogen removal characteristics included Microvirgula aerodenitrificans, Bacillus methylotrophicus, Pseudomonas stutzeri strains T1, YZN-001, and P. stutzeri ZF31 [2,12-15]. Moreover, aerobic denitrification also occurred in natural systems, for example, in the Wadden Sea sediment [16] and horizontal subsurface-flow constructed wetlands [17].

Water-lifting aerators (WLAs) which were installed in reservoirs for water quality improvement has been used widely in recent times [18-20]. This gives us an opportunity to explore aerobic denitrification in situ. Based on our previous study on a pilot scale [2], an aerobic denitrification biofilm performed well with oxygen supplied by WLAs, and the nitrogen removal performance could meet the requirements of Class 3, based on the Chinese Surface Water Environmental Quality Standard (GB3838-2002). During the WLAs operation in an enclosure system in the Zhoucun Reservoir [8], nitrate in the enhanced system decreased from $1.71 \pm 0.01$ to $0.8 \pm 0.06 \mathrm{mg} / \mathrm{L}$, and the control system showed little removal. The total nitrogen (TN) removal rate of the enhanced system reached $38.33 \pm 1.50 \%$. These data suggest that aerobic denitrification is an effective way to decrease the endogenous nitrogen pollution in drinking water reservoirs. Of course, further studies are required to understand the nitrogen removal mechanism [16,17] and water quality improvement mechanism by the WLAs [8].

In this study, we performed a field study in a canyon-shaped drinking water reservoir named Jinpen Reservoir. In the main reservoir (with a surface area of nearly $2 \mathrm{~km}^{2}$ ), eight WLAs were running during our research. Many studies have shown that under anaerobic conditions, pollutants like N, P, and Fe would be released into the overlying water from the sediment [8,18-20]. However, the main function of WLAs is to destroy the stratification and oxygenate the hypolimnion when it is anaerobic. Thus, operation of WLAs provides an aerobic environment that can inhibit sediment release. Simultaneously, the operation can also enhance the indigenous aerobic denitrifiers; as observed, the densities of aerobic denitrifiers and the abundance of denitrification functional genes were both increased by one magnitude compared with that before operation of WLAs. However, in the control area (2 km far away from the WLAs), no obvious increase in aerobic denitrifier densities was observed. Denitrification functional genes (nirS and nirK) were also quantified using real-time polymerase chain reaction (PCR) both in the enhanced and control areas during the operation of WLAs. Biolog technology was used to investigate the microbial metabolic activity and the carbon source utilization. Microbial community variation was also explored to determine which genera of bacterioplankton were dominant in both areas. In the end, we also tried to (1) explore the nitrogen removal performance of the water and surface sediment system in the period of WLAs operation, (2) investigate the microbial metabolic activity and carbon removal efficiency, (3) study the changes in aerobic denitrification bacteria and denitrification functional genes (nirS and nirK), and (4) determine the diversity of the bacterial community and the relationship between the microbial community structure and environment driving factors, especially the bacteria involved in nitrogen cycling. 


\section{Materials and Methods}

\subsection{Sampling Sites and Field Work}

As shown in Figure S1, a canyon-shaped deep drinking water reservoir named Jinpen Reservoir (at latitudes from $34^{\circ} 13^{\prime} \mathrm{N}$ to $34^{\circ} 42^{\prime} \mathrm{N}$ and longitudes from $107^{\circ} 43^{\prime} \mathrm{E}$ to $108^{\circ} 24^{\prime} \mathrm{E}$ ) was our research site, and it supplies $80 \%$ drinking water to $\mathrm{Xi}^{\prime}$ an City, northwest China. Its main reservoir length is $3.5 \mathrm{~km}$. The total capacity of the reservoir is $2.0 \times 10^{8} \mathrm{~m}^{3}$ and its effective capacity is $1.8 \times 10^{8} \mathrm{~m}^{3}$. The main function of the Jinpen Reservoir is urban water supply. Agricultural irrigation, power generation, and flood control are its accessory functions. The reservoir had 8 WLAs installed for water quality improvement. The enhanced area was nearly $50 \mathrm{~m}$ away from the WLAs, whereas the control area was $2 \mathrm{~km}$ away. During the operation of WLAs (15 October to 2 November in 2015), water samples were collected every two days. Every water sample $(0.5,45$, and $90 \mathrm{~m})$ was collected in triplicate. The surface sediment samples in both the enhanced and control areas were collected every five days, in triplicate. Water samples from the enhanced and control areas were stored into pre-cleaned high-density polyethylene bottles. The samples were immediately cooled and were stored at $4{ }^{\circ} \mathrm{C}$ until analysis.

\subsection{Biolog ECO Micro Plate (Carbon Metabolism Characteristics and Diversity of Microbes)}

Biolog is an advanced method of investigating the carbon metabolism, community structure, and microbial diversity in environments. Average well color development (AWCD) of the average microbe activity was used to determine the utilization of carbon sources and metabolism characteristics. Absorbance values at wavelengths of $590 \mathrm{~nm}$ and $750 \mathrm{~nm}$ per hole were subtracted with the absorbance values of the control groups, respectively, and then the absorbance value at $590 \mathrm{~nm}$ was subtracted with the value at $750 \mathrm{~nm}$ in the same group, respectively $\left(C_{590-750}\right)$. Hence, the absorbance value per hole could be obtained. It is notable that a number below 0.06 was recorded as 0 [8]. The formula can be determined as

$$
\mathrm{AWCD}_{590-750}=\Sigma\left(\mathrm{C}_{590-750}\right) / 31 .
$$

where 31 represents the number of carbon source varieties in the Biolog ECO Micro Plate.

Carbon source utilization (non-dimensional) was calculated by the mean values of absorbance for every carbon source in one class. For example, amino acids $=(C L$-arginine + CL-asparagine + CL-phenylalanine + CL-serine + CL-threonine + CL-glutamic acid) $/ 6$.

\subsection{Quantification of nirS and nirK Genes}

Quantification PCR was used to explore the nitrogen removal gene (nirS and nirK) copy numbers in both the enhanced and control areas (7 times from 15 October to 2 November). DNA was extracted from every $2 \mathrm{~L}$ water sample using a Fast DNA kit. Primers for nirS quantification were cd3aF, 5'-GTSAACGTSAAGGARACSGG-3' and R3cd, 5'-GASTTCGGRTGSGTCTTGA-3'. Primers for nirK quantification were F1aCu, 5'-ATYGGCGGVCAYGGCGA-3' and R3Cu, 5'-GCCTCGATCAGRTTRTGGTT-3' [8]. Real-time PCR (qPCR) was performed on the ABI 7500 real-time system (Life Technologies, Carlsbad, CA, USA). SYBR Premix Ex TaqTM (Takara Bio, Dalian, China) was used to perform the amplification reaction. The qPCR amplification of nirS (cd3af/R3cd) and nirK (F1aCu/R3Cu) was performed as described previously [8].

\subsection{Number Counts of Indigenous Aerobic Denitrifiers}

The numbers of indigenous aerobic denitrifiers in both the enhanced and control areas were determined by plate counts and were tested via gradient dilution. The gradient dilutions were prepared as follows: $10^{-3}, 10^{-4}, 10^{-5}$, and $10^{-6}$, and $0.2 \mathrm{~mL}$ of the diluents was streaked onto a solid screening medium (including (g/L): $\mathrm{CH}_{3} \mathrm{COONa}, 0.10 ; \mathrm{NaNO}_{3}, 0.02 ; \mathrm{K}_{2} \mathrm{HPO}_{4} \cdot 3 \mathrm{H}_{2} \mathrm{O}, 0.02 ; \mathrm{CaCl}_{2}, 0.01$; 
$\mathrm{MgCl}_{2} \cdot 6 \mathrm{H}_{2} \mathrm{O}, 0.01$; and agar, 20; $\mathrm{pH}$ 7.2) in triplicate, and incubated at $30{ }^{\circ} \mathrm{C}$ for five days. Single colonies were then harvested and counted [8].

\subsection{Illumina Miseq Sequencing}

The Illumina Miseq Sequencing platform was used to explore the microbial community composition. The DNA extracted from water samples was amplified by PCR using primers 27F (5'-AGAGTTTGATCCTGGCTCAG-3') and 338R (5'-TGCTGCCTCCCGTAGGAGT-3') targeting the V2 region of bacterial $16 \mathrm{~S}$ rRNA genes. The PCR products were then sequenced using an Illumina Miseq Sequencing platform according to the standard protocols specified by the Shanghai Majorbio Bio-pharm Technology Co., Ltd., China. Low quality sequences were removed.

\subsection{Physical Analysis}

Temperature, DO (dissolved oxygen), $\mathrm{pH}, \mathrm{Chl}-\mathrm{a}$ (chlorophyll-a), turbidity, and ORP (oxidation-reduction potential) were determined in situ every $2 \mathrm{~m}$ using a Hach multi-probe water quality analyzer (Hydrolab DS5, Loveland, CO, USA).

\subsection{Chemical Analysis in Water}

The concentrations of TN (total nitrogen), nitrate, ammonia, and nitrite were determined using a SEAL AA3 HR Auto Analyzer (SEAL, Hamburger, Germany). TOC (total organic carbon) concentrations were measured with a TOC-L total organic carbon analyzer (Shimadzu, Kyoto, Japan).

\subsection{Chemical Analysis in Sediments}

Sediment samples were air-dried and ground before analysis. Sediment total nitrogen (TN) was determined by $\mathrm{Zn}-\mathrm{Cd}$ reduction spectrophotometry after digestion with potassium peroxodisulfate and microwaving $\left(121^{\circ} \mathrm{C}, 1 \mathrm{~h}\right.$ ). Sediment total phosphorus (TP) was detected using the Mo-Sb colorimetric method. Sediment organic carbon (OC) was determined by the potassium dichromate volumetric method (Mack and D'Antonio, 2012).

\subsection{Data Analysis}

The fundamental analysis, abundance-based coverage estimators (ACE), Chao richness estimator, coverage, and the Shannon and Simpson index were calculated by MOTHUR. The gradient length of the longest axis explored by detrended correspondence analyses (DCA) was less than 3 SD (standard deviation) units. This indicates that the species exhibited linear responses to environmental gradients and therefore, further analyses were conducted using redundancy analysis (RDA) ordination response models [8].

\section{Results and Discussion}

\subsection{Spatial and Temporal Variation of Environmental Factors in the Enhanced Area}

The operation of WLAs decreased the temperature (T) of the surface water and increased that of the bottom water in the enhanced area. As shown in Figure 1, $\mathrm{T}$ of the surface water had decreased from $17.1 \pm 0.21{ }^{\circ} \mathrm{C}$ (15 October) to $14.8 \pm 0.12{ }^{\circ} \mathrm{C}$ ( 2 November), and $\mathrm{T}$ of the bottom water had increased from $10.1 \pm 0.05^{\circ} \mathrm{C}$ ( 15 October) to $14.3 \pm 0.09^{\circ} \mathrm{C}$ ( 2 November). $\mathrm{T}$ of the vertical water column was homogeneous. The increase in $\mathrm{T}$ of the middle and bottom water might help increase the activity of indigenous microbes. DO of the water column was increased, especially that of the bottom water (from $0 \mathrm{mg} / \mathrm{L}$ (15 October) to $9.8 \pm 0.19 \mathrm{mg} / \mathrm{L}$ (2 November)). Thus, on 2 November, the T and DO of the enhanced area were maintained at a nearly homogeneous state. The $\mathrm{pH}$ and ORP (oxidation-reduction potential) of the water column increased gradually during the operation. The ORP of the bottom water especially increased to $504 \mathrm{mV}$ from $25 \mathrm{mV}$. Somehow, the turbidity of the water column showed a decreasing trend from $22.2 \pm 0.2 \mathrm{NTU}$ (maximum value on 15 October) to $8.1 \pm 0.1 \mathrm{NTU}$ (maximum 
value on 2 November). CHl-a varied from $2.65 \pm 0.18 \mu \mathrm{g} / \mathrm{L}$ to $1.09 \pm 0.1 \mu \mathrm{g} / \mathrm{L}$, and the $\mathrm{CHl}-\mathrm{a}$ concentration in the water column was also homogeneous.

Compared with the enhanced area, there was little spatial and temporal variation of environmental factors in the control area. As seen in Figure S2, the T, DO, pH, turbidity, ORP, and CHl-a showed little change in the water column in the control area from 15 October to 2 November.

A non-operation year (2011) for WLAs was proposed for some comparison with 2015. As shown in Figure S3, on nearly the same date in 2011, the stratification of Jinpen Reservoir was stable, and the DO concentration in the bottom water was maintained at $0 \mathrm{mg} / \mathrm{L}$ until 31 October in 2011. From the results of the control area (2015) and those obtained in 2011, we can conclude that the mixing and oxygenation functions of WLAs were very efficient. Through the operation of WLAs, the DO concentrations of the reservoir-especially in the bottom water-were greatly improved.
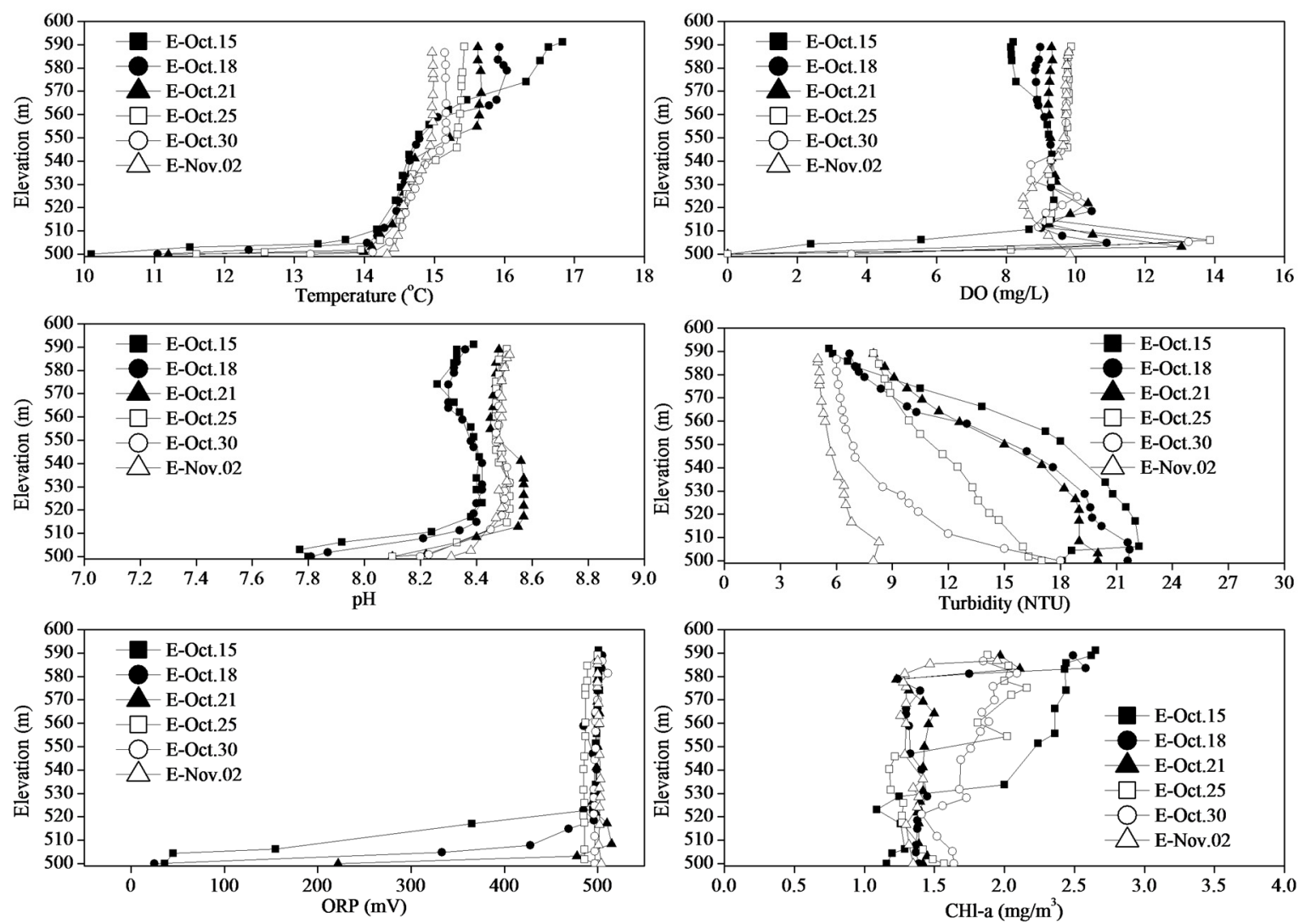

Figure 1. Variation of $\mathrm{T}, \mathrm{DO}, \mathrm{pH}$, turbidity, $\mathrm{ORP}$, and $\mathrm{CHl}-\mathrm{a}$ in the enhanced area during the operation of WLAs (E-indicates "enhanced area").

\subsection{Nitrogen Removal in the Enhanced Area}

The changes in TN, nitrate, ammonia, and nitrite at the enhanced and control areas are shown in Figure 2. In the enhanced area, surface TN concentrations decreased from $1.72 \pm 0.06 \mathrm{mg} / \mathrm{L}$ (15 October) to $1.21 \pm 0.05 \mathrm{mg} / \mathrm{L}$ (2 November), and the removal rate (see Figure S4) reached $29.1 \pm 0.8 \%$. Compared with the control area, the surface TN concentrations decreased from $1.68 \pm 0.10 \mathrm{mg} / \mathrm{L}$ (15 October) to $1.55 \pm 0.03 \mathrm{mg} / \mathrm{L}$ ( 2 November), and the removal rate was only $7.7 \pm 1.8 \%$. The TN in the middle and bottom waters showed the same trend as that in the surface water. The TN in the bottom water decreased from $2.36 \pm 0.12 \mathrm{mg} / \mathrm{L}$ (15 October) to $1.20 \pm 0.04 \mathrm{mg} / \mathrm{L}$ ( 2 November), and the removal rate reached as high as $47.5 \pm 0.5 \%$. 

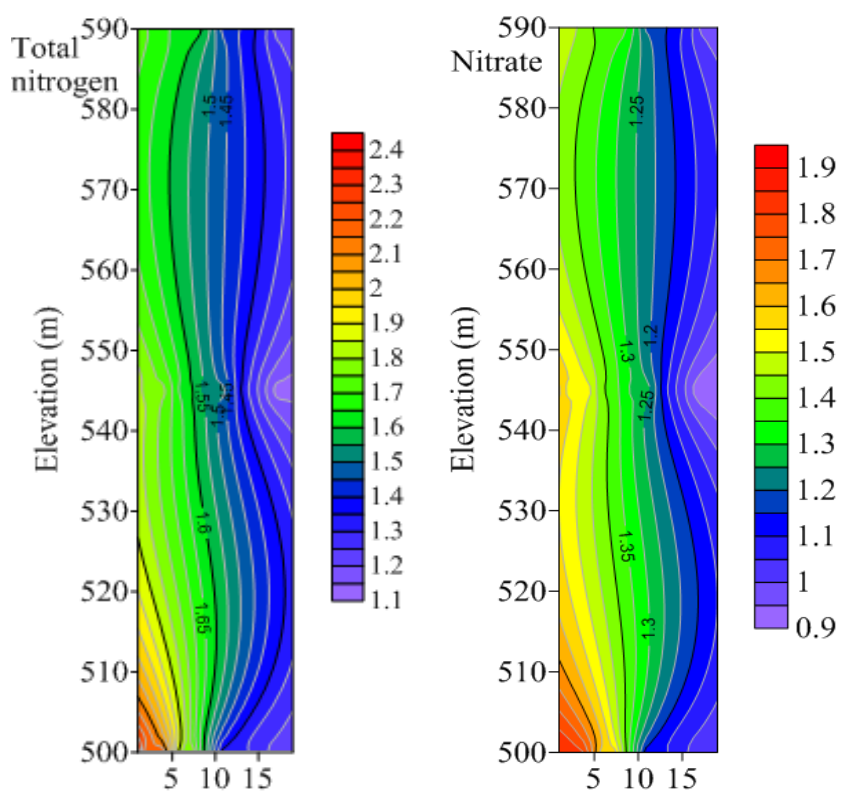



Operation time of WLAs (d)
Operation time of WLAs (d)

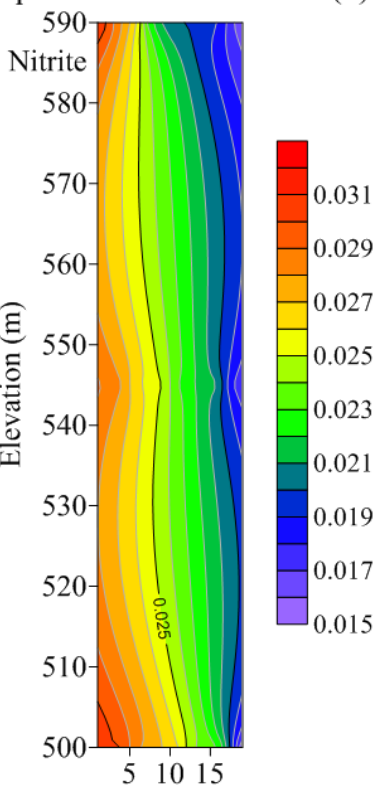

Operation time of WLAs (d)

Figure 2. Variations in the concentration of total nitrogen, nitrate, ammonia, and nitrite during the operation of WLAs in the enhanced area.

In the Jinpen Reservoir, nitrate is the main form of nitrogen, accounting for $83.5 \pm 5.9 \%$. The nitrate removal rates (shown in Figure S5) of the surface, middle, and bottom water in the enhanced area were $33.6 \pm 2.9 \%, 43.5 \pm 2.6 \%$, and $44.4 \pm 3.2 \%$, respectively. However, compared with the enhanced area, the nitrate removal rate of the surface, middle, and bottom water in the control area was only $11.1 \pm 0.9 \%, 13.5 \pm 0.6 \%$, and $10.4 \pm 0.2 \%$, respectively. During the operation, no nitrite accumulation was observed both in the enhanced and control areas (Figure S6). Nitrite in both areas was maintained at low concentrations, and the maximum concentration in the enhanced area reached $0.04 \pm 0.005 \mathrm{mg} / \mathrm{L}$, decreasing gradually from 15 October to 2 November, and the nitrite in the control area was maintained at $0.03 \pm 0.004 \mathrm{mg} / \mathrm{L}$. As seen in Figure S7, the ammonia concentration in all three water layers showed a decreasing trend, especially in the bottom water, decreasing from $0.48 \pm 0.06 \mathrm{mg} / \mathrm{L}$ to $0.12 \pm 0.02 \mathrm{mg} / \mathrm{L}$, and its removal rate reaching $72.5 \pm 2.5 \%$. No ammonia 
accumulation was observed during the nitrate removal period in the enhanced area. Compared with the enhanced area, the ammonia removal rate in the control area was quite small, $19.2 \pm 0.5 \%$. In order to explore where the nitrogen had gone, the nitrogen content in the sediments was also determined.

During the operation of WLAs, the surface sediments in both the enhanced and control areas were determined on 15 October, 21 October, 28 October, and 2 November, and the results are shown in Table 1. The OC and TN concentrations in the enhanced area had all decreased from $3.42 \pm 0.20 \%$ and $1522 \pm 66 \mathrm{mg} / \mathrm{kg}$ to $2.66 \pm 0.12 \%$ and $1242 \pm 61 \mathrm{mg} / \mathrm{kg}$, and their removal rates were $22.2 \pm 6.5 \%$ and $18.4 \pm 3.6 \%$, respectively. In contrast, the OC and TN concentrations in the control area were slightly increased. The reason of this increase may be inflow sedimentation as described in our previous study [8].

Table 1. Changes in OC and TN concentrations in the surface sediment $(0-1 \mathrm{~cm})$ at the enhanced and control areas during the operation of WLAs, in triplicate

\begin{tabular}{lccc}
\hline Sampling Site & Date & OC (\%) & TN (mg/kg) \\
\hline & 15 October & $3.42 \pm 0.20$ & $1522 \pm 66$ \\
Enhanced Area & 21 October & $2.92 \pm 0.11$ & $1471 \pm 43$ \\
& 28 October & $2.78 \pm 0.11$ & $1313 \pm 56$ \\
& 2 November & $2.66 \pm 0.12$ & $1242 \pm 61$ \\
\hline \multirow{5}{*}{ Control Area } & 15 October & $3.33 \pm 0.12$ & $1644 \pm 72$ \\
& 21 October & $3.48 \pm 0.09$ & $1687 \pm 54$ \\
& 28 October & $3.43 \pm 0.08$ & $1744 \pm 36$ \\
& 2 November & $3.64 \pm 0.12$ & $1751 \pm 44$ \\
\hline
\end{tabular}

Note: "enhanced area" was nearly $50 \mathrm{~m}$ away from the WLAs, "control area" was $2 \mathrm{~km}$ away from the WLAs. "OC" means organic carbon in sediment; "TN" means total nitrogen in sediment.

Based on these results, the nitrogen content in both the water and the sediment of the enhanced area was significantly removed. Thus, the activity of indigenous aerobic denitrifiers may be enhanced in the enhanced area in situ. As is already known, aerobic denitrification bacteria have been found in natural environments such marine sediments, constructed wetlands, and reservoirs [21-23], and have been reported only by these three studies. In this study, we also observe the phenomenon of nitrogen removal in a drinking water reservoir in situ with nitrite and ammonia accumulation. We consider that the indigenous aerobic denitrifiers were activated by the in situ operation of WLAs. Deviating from our previous research [23], the present study was performed in the field with the in situ operation of eight WLAs, and not in an enclosure system. The results obtained in the study of the enhanced area were consistent with those described before. However, a lower nitrogen removal rate was also found in the control area, which was inconsistent with previous results [23]. In our study, ammonia and nitrite were simultaneously removed via nitrification and denitrification, and similar results were obtained in previous studies $[17,23]$. In order to clearly understand whether the activity of indigenous aerobic denitrifiers had been improved and to determine the growth of indigenous aerobic denitrifiers, the Biolog method and plate count method were used for both the enhanced and control areas.

\subsection{Carbon Metabolism Characteristics and Carbon Sources Utilization in the Enhanced and Control Areas}

The AWCD value reflects the microbial microflora with different carbon sources and the change rate showed the metabolic activity of the microbial microflora [17]. A higher AWCD value and growth rate indicates a higher metabolic activity. During the operation of the WLAs, water samples $(0.5$, 45, and $90 \mathrm{~m}$ ) were tested using the Biolog ECO plate on 15 October, 25 October, and 2 November, respectively. The results are shown in Figure $3 \mathrm{~A}-\mathrm{C}$. The increase of AWCD mainly occurred in the first $120 \mathrm{~h}$, and then stabilized. This means that the carbon source utilization mainly occurred in the first $120 \mathrm{~h}$. According to the $120 \mathrm{~h}$ data point, for the bottom in the enhanced area, the AWCD value increased from $0.53 \pm 0.08$ ( 15 October) to $0.75 \pm 0.11$ ( 25 October), and then to $0.87 \pm 0.12$ (2 November). Compared with the enhanced area, these values in the control area were $0.60 \pm 0.04$ 
(15 October), $0.54 \pm 0.05$ (25 October), and $0.49 \pm 0.02$ (2 November), respectively, demonstrating a decreasing trend. As shown in Figure S8, the increase trend line of enhanced area of $0.5 \mathrm{~m}$ water was $y=0.0668 x, y=0.1029 x$, and $y=0.1318 x$, respectively. The increase rate was obviously improved. Compared with the control area of $0.5 \mathrm{~m}$ water was $y=0.0852 x, y=0.0814 x$, and $y=0.0770 x$, respectively. It is clear that the in situ operation of WLAs resulted in improved metabolic activity of the indigenous microbes in the enhanced area, whereas that in the control area had reduced naturally.

Figure 3D-F showed the results of carbon source utilization. All the carbon sources were classified into six types: carbohydrates, amino acids, esters, alcohols, amines, and carboxylic acids. Absorbance was used to represent a carbon source utilization quantity. The carbon source utilization quantity was generally improved by the operation of WLAs. The total carbon sources utilization quantities in the enhanced area on 15 October were $4.49 \pm 0.12(0.5 \mathrm{~m}), 3.74 \pm 0.15(45 \mathrm{~m})$, and $3.86 \pm 0.12$ $(90 \mathrm{~m})$. On 25 October, these were increased to $5.12 \pm 0.21(0.5 \mathrm{~m}), 4.41 \pm 0.18(45 \mathrm{~m})$, and $4.87 \pm 0.21$ $(90 \mathrm{~m})$. On 2 November, the total carbon source utilization quantities in the enhanced area had greatly increased compared to those on 15 October, which were $6.60 \pm 0.32(0.5 \mathrm{~m}), 5.50 \pm 0.25(45 \mathrm{~m})$, and $5.75 \pm 0.12(90 \mathrm{~m})$. Compared with the enhanced area, these values in the control area showed little increase. The total carbon source utilization quantities showed the same trend as TOC variation. As seen in Figure S5, TOC concentrations in the enhanced area decreased from $3.69 \pm 0.12$ (15 October, $0.5 \mathrm{~m}$ ), $3.42 \pm 0.20$ ( 15 October, $45 \mathrm{~m}$ ), and $4.02 \pm 0.18$ ( 15 October, $90 \mathrm{~m}$ ) to $2.72 \pm 0.15$ ( 2 November, $0.5 \mathrm{~m}), 2.65 \pm 0.18$ ( 2 November, $45 \mathrm{~m}$ ), and $2.85 \pm 0.20$ (2 November, $90 \mathrm{~m}$ ). The TOC removal rates of the enhanced area were $25.5 \pm 0.8 \%(0.5 \mathrm{~m}), 23.8 \pm 1.2 \%(45 \mathrm{~m})$, and $28.2 \pm 2.1 \%(90 \mathrm{~m})$, and those of the control area were only $3.4 \pm 0.4 \%(0.5 \mathrm{~m}), 6.5 \pm 1.2 \%(45 \mathrm{~m})$, and $5.6 \pm 0.5 \%(90 \mathrm{~m})$.
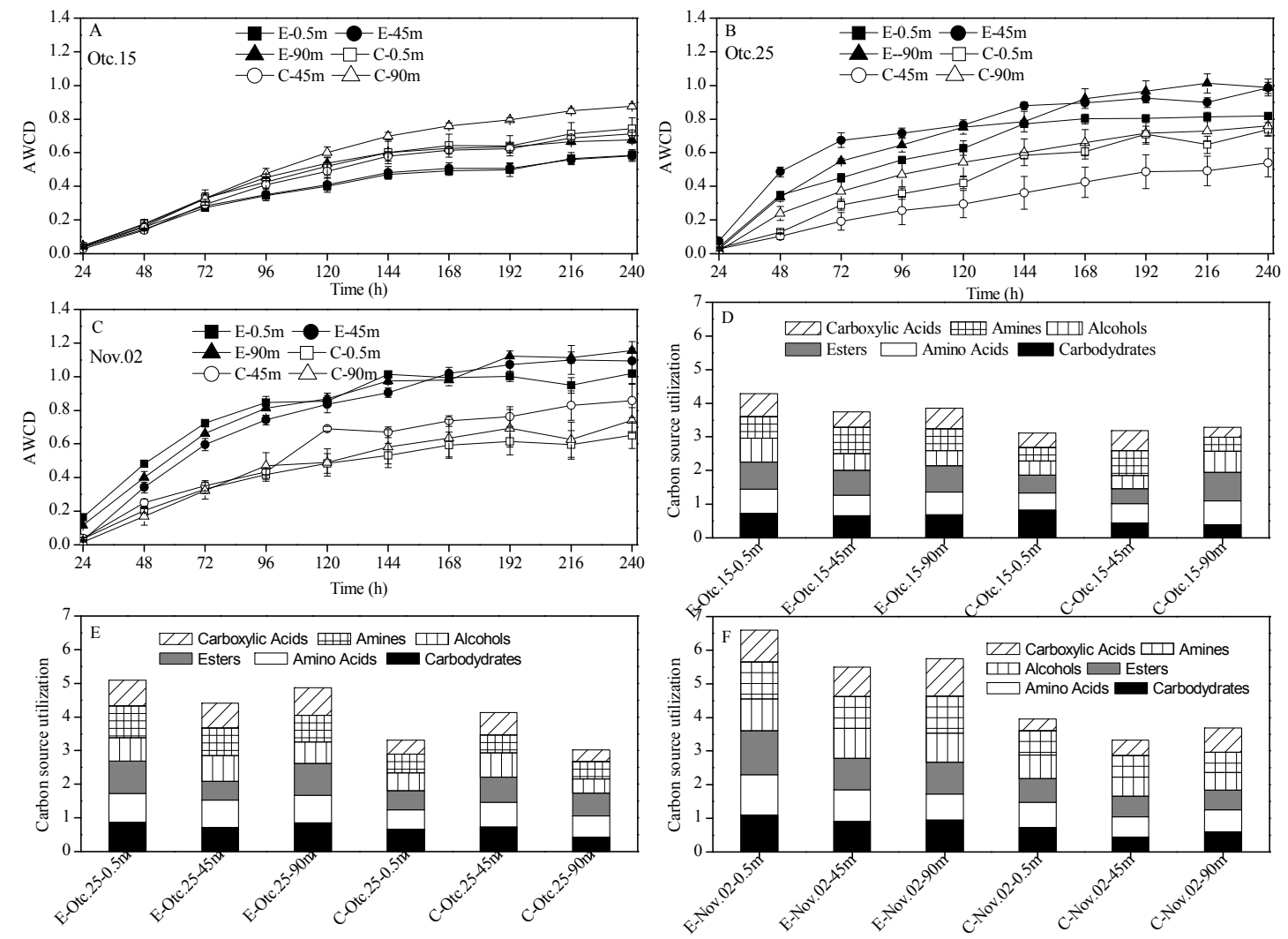

Figure 3. AWCD and carbon source utilization variation of microbes in the enhanced and control areas during the operation of WLAs ((A,D): 15 October, (B,E): 25 October, $(\mathbf{C}, \mathbf{F})$ : 2 November; E-indicates "enhanced area"; C-indicates "control area"). 
The results of the Biolog ECO Micro Plate and TOC (Figure S9) determination showed that the metabolic activity and the total carbon source utilization quantities of the indigenous aerobic denitrifiers were improved in the enhanced area compared with those in the control area. However, the amount of aerobic denitrifiers and the number of nitrogen removal functioning genes were unknown. Therefore, it was necessary to quantify the aerobic denitrifiers and nitrogen removal functioning genes in these areas.

\subsection{Density Changes for Aerobic Denitrifiers and Denitrification Functional Genes nirK and nirS}

As seen in Figure $4 \mathrm{~A}$, the densities of the indigenous aerobic denitrifiers were determined through the plate count method in both the enhanced and the control areas during the operation of WLAs. The number of aerobic denitrifiers in the enhanced area showed an increasing trend from $2.14 \pm 0.08$ $\times 10^{4} \mathrm{cfu} / \mathrm{mL}(0.5 \mathrm{~m}, 15$ October $), 1.34 \pm 0.05 \times 10^{4} \mathrm{cfu} / \mathrm{mL}(45 \mathrm{~m}, 15$ October $)$, and $0.78 \pm 0.02 \times$ $10^{4} \mathrm{cfu} / \mathrm{mL}$ (90 m, 15 October) to $6.06 \pm 0.18 \times 10^{4} \mathrm{cfu} / \mathrm{mL}(0.5 \mathrm{~m}, 2$ November $), 5.84 \pm 0.09 \times 10^{4}$ $\mathrm{cfu} / \mathrm{mL}\left(45 \mathrm{~m}, 2\right.$ November), and $4.67 \pm 0.10 \times 10^{4} \mathrm{cfu} / \mathrm{mL}(90 \mathrm{~m}, 2$ November). The number of aerobic denitrifiers was increased by $2-5$ times after the operation of WLAs. No obvious increase in aerobic denitrifiers was observed in the control area and their number was maintained at $0.98 \pm 0.06$ $\times 10^{4} \mathrm{cfu} / \mathrm{mL}$ to $1.85 \pm 0.12 \times 10^{4} \mathrm{cfu} / \mathrm{mL}$ during the operation in all water layers.
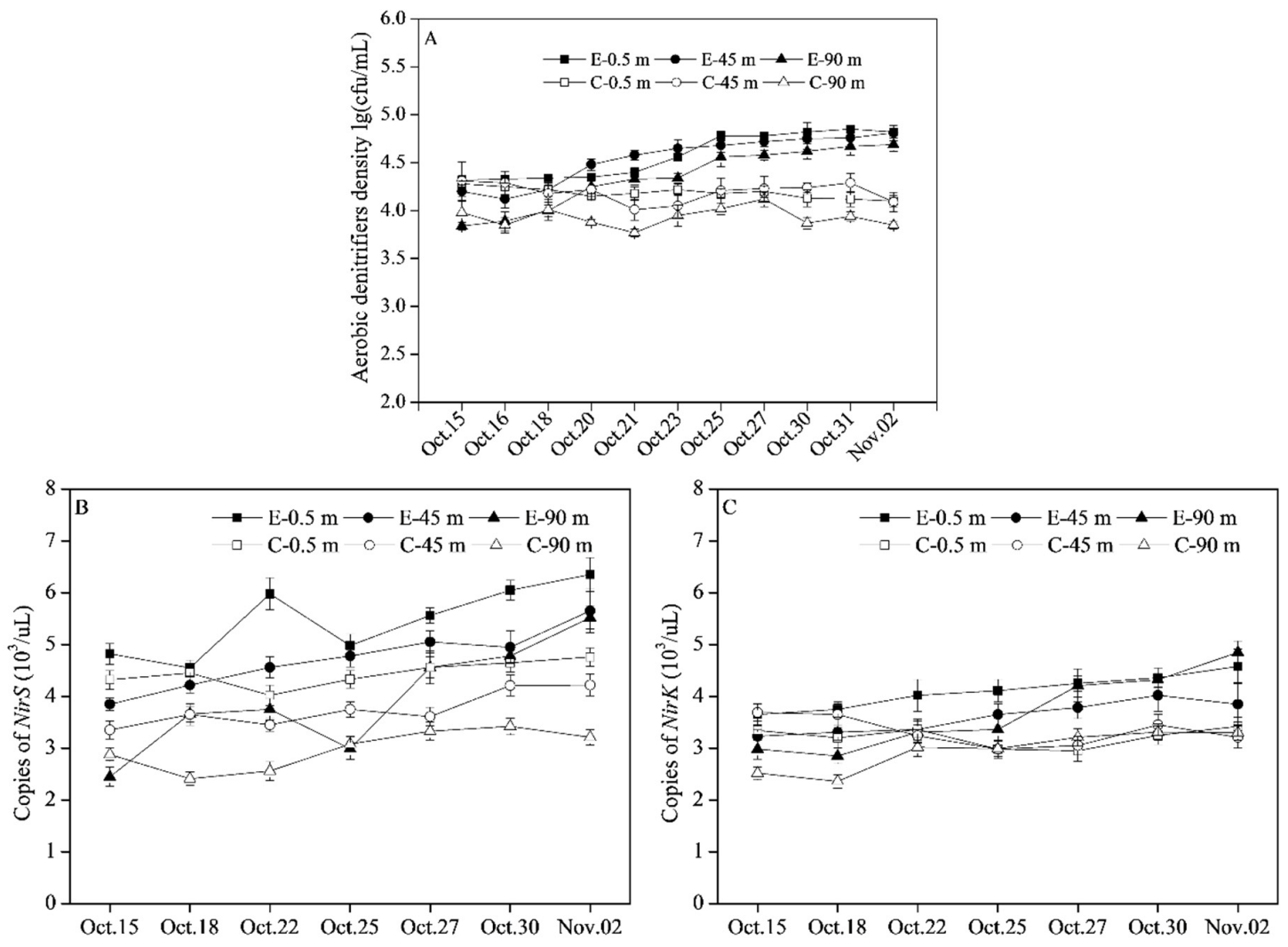

Figure 4. Variation of aerobic denitrifier density and the genes nirS and nirK in the enhanced and control areas ((A): 15 October, (B): 25 October, (C): 2 November; E—indicates "enhanced area"; C—indicates "control area").

Deviating from our previous study [23] in the Zhoucun Reservoir with the enclosure system, the number of aerobic denitrifiers in the enhanced area $(0.5,45$, and $90 \mathrm{~m})$ all showed an increasing trend throughout the monitoring period, and no decreasing trend was observed. The reason for this may be that in the field scale, there is no lack of TOC due to the severe exchange between water bodies (Figure S8). Moreover, the number of aerobic denitrifiers in the enhanced area was less than that in the 
enclosure system [23], and so the nitrogen removal rate in this study was also a slightly lower than that in the enclosure system.

Nitrite reductase occurs in two structurally different but functionally equivalent forms: nirK, containing copper, and nirS containing iron [23]. The nirK and nirS genes have been used to examine denitrifying bacteria in many environments [22-27]. Thus, quantification of denitrifying genes is of great importance for better understanding of denitrifying activity in the reservoir. As is known, few studies have focused on quantifying nirK and nirS. Similar to our previous study, we quantified nirK and nirS by real-time quantitative in both the enhanced and control areas.

As seen in Figure 4B,C, both nirK and nirS in the enhanced area were increased during the operation of WLAs. On 15 October, nirK in the enhanced area showed $(4.82 \pm 0.12) \times 10^{4}$ copies $/ \mu \mathrm{L}$ $(0.5 \mathrm{~m}),(3.85 \pm 0.08) \times 10^{4}$ copies $/ \mu \mathrm{L}(45 \mathrm{~m})$, and $(2.45 \pm 0.13) \times 10^{4}$ copies $/ \mu \mathrm{L}(0.5 \mathrm{~m})$. After the operation, on 2 November, these values increased to $(6.35 \pm 0.24) \times 10^{4}$ copies $/ \mu \mathrm{L}(0.5 \mathrm{~m}),(5.65 \pm 0.15)$ $\times 10^{4}$ copies $/ \mu \mathrm{L}(45 \mathrm{~m})$, and $(5.52 \pm 0.18) \times 10^{4}$ copies $/ \mu \mathrm{L}(0.5 \mathrm{~m})$. The nirK copy number in the control area showed little increase in all the water layers and was maintained at $(2.41-4.76) \times 10^{4}$ copies $/ \mu \mathrm{L}$. The nirS copy number showed the same trend as that of nirK. The nirS copy number in the enhanced area increased by $0.24-0.63$ times via the in situ operation. In the control area, the nirS genes showed a slight decrease.

From the above results, we can conclude that both aerobic denitrifier density and the denitrifying gene copy numbers were increased via the in situ operation of WLAs in the enhanced area compared with the control area. The Biolog ECO plate results showed that microbial metabolic activity had also improved greatly. Thus, the nitrogen was removed by the indigenous aerobic denitrifiers via the in situ operation of WLAs.

\subsection{Spatial and Temporal Changes of Microbial Community}

Miseq high-throughput sequencing was used to explore the microbial community changes in the enhanced and control areas. As shown in Table 2, of the 800,156 sequenced reads, 15,627 OTUs (operational taxonomic units) with $97 \%$ similarity were obtained. The number of OTUs obtained from the 12 water samples in the enhanced area wad 8264, which was higher than that obtained from samples of the control area (7363 OTUs). Thus, operation of the WLAs improved the microbial diversity in the enhanced area compared with that in the control area. The highest OTU number was obtained in the enhanced area at $45 \mathrm{~m}$ (15 October). The lowest number was obtained in the control area at $0.5 \mathrm{~m}$ (15 October).

The AEC and Chao diversity estimators, as shown in Table 2, varied mainly across depths. AEC diversity estimators ranged from 612 to 1205 and Chao diversity estimators varied from 499 to 1122 across depths. The average coverage of the enhanced and control areas was 0.9938 and 0.9943 , respectively. This showed that the real structure of microbial communities was wonderfully reflected [28]. 
Table 2. Spatial and temporal distribution of the microbial community diversity and richness estimators in the enhanced and control areas

\begin{tabular}{|c|c|c|c|c|c|c|c|c|c|c|c|c|c|c|c|}
\hline \multirow{4}{*}{ Period } & \multirow{4}{*}{$\begin{array}{l}\text { Water } \\
\text { Depth }\end{array}$} & \multicolumn{7}{|c|}{ Enhanced Area } & \multicolumn{7}{|c|}{ Control Area } \\
\hline & & \multirow{3}{*}{$\begin{array}{l}\text { Reads } \\
\text { Number }\end{array}$} & \multicolumn{6}{|c|}{0.97 Level } & \multirow{3}{*}{$\begin{array}{l}\text { Reads } \\
\text { Number }\end{array}$} & \multicolumn{6}{|c|}{ 0.97 Level } \\
\hline & & & \multirow{2}{*}{ OTUs } & \multicolumn{2}{|c|}{ Diversity } & \multirow{2}{*}{ Coverage } & \multicolumn{2}{|c|}{ Richness } & & \multirow{2}{*}{ OTUs } & \multicolumn{2}{|c|}{ Diversity } & \multirow{2}{*}{ Coverage } & \multicolumn{2}{|c|}{ Richness } \\
\hline & & & & ACE & Chao1 & & Shannon & Simpson & & & ACE & Chao1 & & Shannon & Simpson \\
\hline \multirow{3}{*}{$\begin{array}{c}15 \\
\text { October }\end{array}$} & $0.5 \mathrm{~m}$ & 24,639 & 712 & 931 & 923 & 0.9916 & 4.55 & 0.0275 & 38,061 & 363 & 612 & 499 & 0.9970 & 3.26 & 0.1035 \\
\hline & $45 \mathrm{~m}$ & 39,804 & 852 & 1034 & 1021 & 0.9951 & 4.85 & 0.0198 & 30,552 & 544 & 708 & 738 & 0.9949 & 3.73 & 0.0921 \\
\hline & $90 \mathrm{~m}$ & 40,082 & 765 & 1019 & 1029 & 0.9943 & 4.38 & 0.0313 & 29,841 & 629 & 1026 & 905 & 0.9932 & 4.28 & 0.0346 \\
\hline \multirow{3}{*}{$\begin{array}{c}21 \\
\text { October }\end{array}$} & $0.5 \mathrm{~m}$ & 27,963 & 650 & 1105 & 1004 & 0.9920 & 4.32 & 0.029 & 26,986 & 685 & 918 & 908 & 0.9924 & 4.41 & 0.0327 \\
\hline & $45 \mathrm{~m}$ & 29,817 & 579 & 740 & 780 & 0.9947 & 4.22 & 0.0338 & 34,268 & 702 & 914 & 947 & 0.9941 & 4.37 & 0.034 \\
\hline & $90 \mathrm{~m}$ & 30,418 & 654 & 858 & 877 & 0.9938 & 4.45 & 0.0259 & 30,516 & 846 & 1111 & 1122 & 0.9918 & 4.91 & 0.0171 \\
\hline \multirow{3}{*}{$\begin{array}{c}28 \\
\text { October }\end{array}$} & $0.5 \mathrm{~m}$ & 33,431 & 649 & 953 & 843 & 0.9946 & 4.47 & 0.0256 & 27,036 & 465 & 600 & 641 & 0.9952 & 4.04 & 0.0441 \\
\hline & $45 \mathrm{~m}$ & 31,302 & 715 & 960 & 981 & 0.9930 & 4.47 & 0.0261 & 33,172 & 595 & 758 & 773 & 0.9953 & 4.23 & 0.0379 \\
\hline & $90 \mathrm{~m}$ & 38,056 & 768 & 1007 & 1018 & 0.9942 & 4.33 & 0.0397 & 39,454 & 654 & 820 & 839 & 0.9958 & 4.38 & 0.0333 \\
\hline \multirow{3}{*}{$\begin{array}{c}2 \\
\text { November }\end{array}$} & $0.5 \mathrm{~m}$ & 19,696 & 566 & 905 & 810 & 0.9905 & 4.15 & 0.0402 & 42,439 & 461 & 617 & 616 & 0.9968 & 3.59 & 0.0566 \\
\hline & $45 \mathrm{~m}$ & 46,082 & 699 & 1045 & 952 & 0.9957 & 4.34 & 0.0305 & 31,783 & 702 & 948 & 934 & 0.9932 & 4.09 & 0.0473 \\
\hline & $90 \mathrm{~m}$ & 45,379 & 655 & 1041 & 882 & 0.9955 & 3.95 & 0.0502 & 29,379 & 717 & 1205 & 1065 & 0.9914 & 4.15 & 0.0405 \\
\hline
\end{tabular}


As shown in Figure 5, 15,627 OTUs with 97\% similarity were affiliated with 11 main phyla including Proteobacteria, Bacteroidetes, Cyanobacteria, Planctomycetes, Nitrospirae, Actinobacteria, Firmicutes, Chloroflexi, Acidobacteria, Verrucomicrobia, and Deinococcus-thermus. Both in the enhanced and control areas, the phyla varied significantly across different periods. Similar to the results from the Zhoucun Reservoir study, Proteobacteria was the largest dominant population in the Jinpen Reservoir ranging from $29 \%$ to $50 \%$. In the control area, on 15 October, Cyanobacteria were the dominant population, but it decreased during the monitoring period. In the enhanced area, Cyanobacteria decreased from $14.9 \%$ (15 October) to $1.7 \%$ (2 November). Bacteroidetes was also a dominant population in both the enhanced and control areas ranging from $6.1 \%$ to $26.4 \%$ varying from depth to depth. The Actinobacteria phylum varied significantly from $2.5 \%$ to $39.1 \%$, and with the percentage in the enhanced area usually being higher than that in the control.

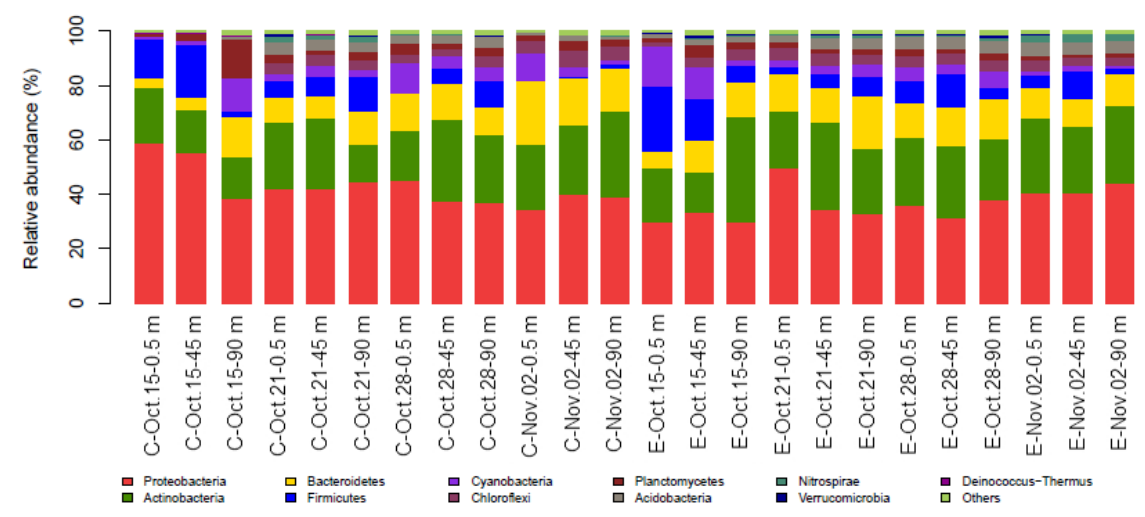

Figure 5. Variation of microbial phyla in the enhanced and control areas (E-indicates "enhanced area"; C-indicates "control area").

Microbial compositions varied greatly across different depths and dates. The abundance of the dominant aerobic denitrifying bacterial genera in the enhanced and the control areas during the operation of WLAs are shown in Figure 6. In the enhanced area, the hgcI_clade (6.0-22.5\%), LD12_freshwater_group_norank (5.5-14.5\%), Bacillus (1.0-11.2\%), CL500-29_marine_group (4.5-13.8\%), and Limnohabitans (1.9-13.5\%) were the dominant genera. During the operation of WLAs, the hgcI_clade (mean value of three water layers) increased from 11.0\% (15 October) to 17.9\% (2 November), the LD12_freshwater_group_norank increased from 6.2\% (15 October) to $11.3 \%$ (2 November), whereas the Bacillus decreased from $7.6 \%$ (15 October) to $3.1 \%$ (2 November).
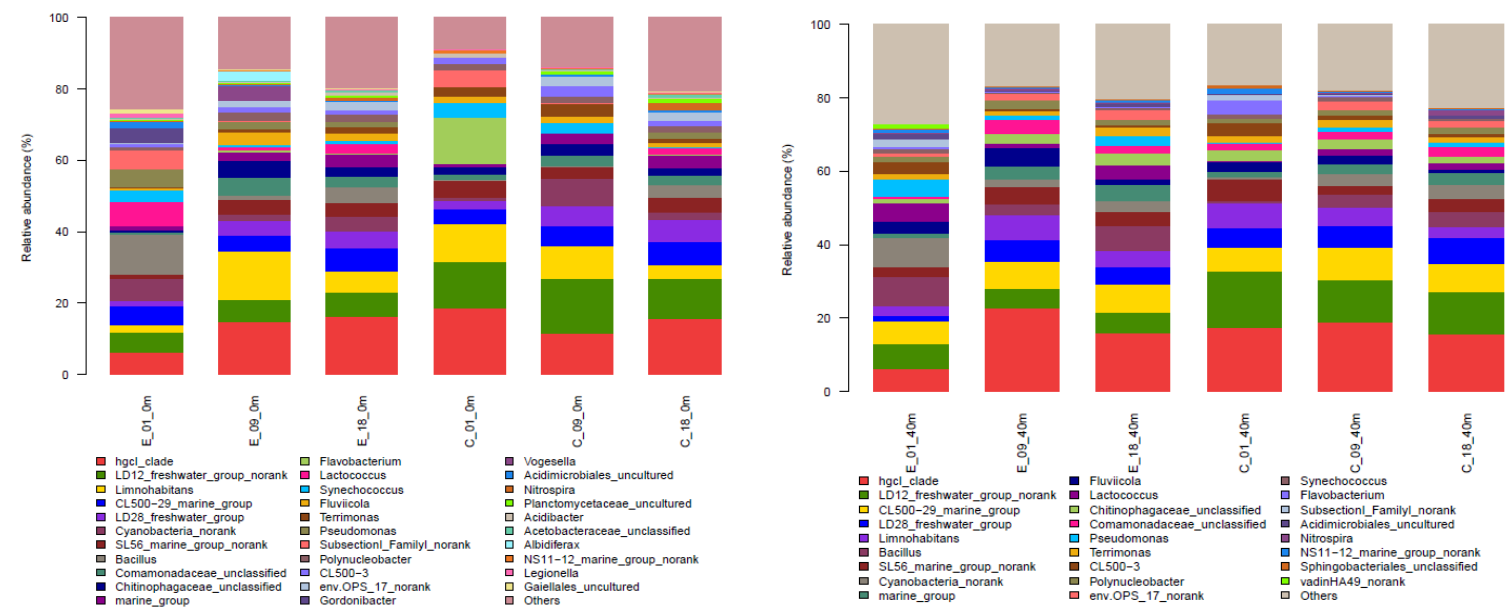

Figure 6. Cont. 


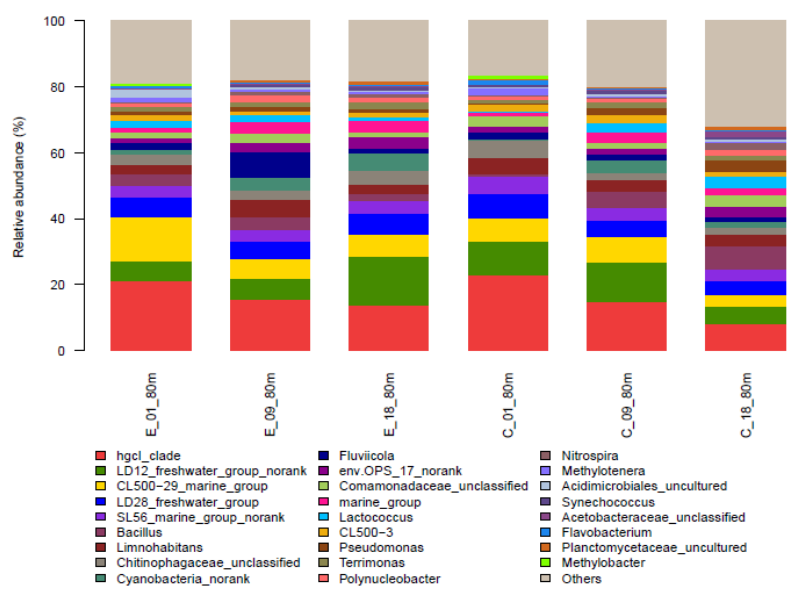

Figure 6. Abundance of the dominating aerobic denitrifying genus in the enhanced and control water layers during the operation of WLAs ("E-01-0m" indicates "enhanced area, the first day of WLAs operation, surface water $0.5 \mathrm{~m}$ "; “C-09-90" indicates "control area, the ninth day of WLAs operation, bottom water $\left.90 \mathrm{~m}^{\prime \prime}\right)$.

\subsection{Variation of Nitrogen Removal Bacteria}

Considering the nitrogen removal performance of indigenous aerobic denitrifiers in the enhanced area via the in situ operation of WLAs, analyzing the variation in nitrogen functional bacteria is of great importance.

A previous study demonstrated that Proteobacteria (especially Acidovorax and Hydrogenophaga) were involved in nitrogen cycling [29]. In the enhanced area, the percentage of Acidovorax increased by 15 times from less than $0.01 \%$ ( 15 October) to $0.15 \%$ ( 2 November). Novosphingobium including the aerobic denitrifiers (ZHF2, GenBank no. KP717095) and ZHF8, GenBank no. KP717087) isolated from the Zhoucun Reservoir [8] increased from less than $0.01 \%$ (15 October) to $0.10 \%$ (2 November). The Hydrogenophaga in the enhanced area increased from $0 \%$ (15 October) to $0.05 \%$ ( 2 November). The aerobic denitrifiers Pseudomonas and Methylophaga increased from less than $0.01 \%$ and $0.02 \%$ to $0.06 \%$ and $0.05 \%$, respectively. The aerobic denitrifiers Sphingomonadaceae and Bacteroidetes (ZMF6, GenBank no. KP717084) were also increased via the operation of WLAs.

Thus, it is clear that the activities and densities of the indigenous aerobic denitrifiers listed above were greatly improved via the WLAs operation. This is the main reason for nitrogen removal in the enhanced area. Future research should be focused on the variation in the microbial community of the surface sediment in both the enhanced and control areas. Moreover, the cultivation, enrichment, and utilization of indigenous aerobic denitrifiers in other water bodies should also be explored.

\subsection{PCA of Microbial Communities}

The principal component analysis methodology was used to explore the spatial and temporal variation in the bacterial community across water samples. As shown in Figure S9, the first two principle components (PC1 and PC2) closely approached $65.87 \%$ and the accumulated contributions of PC1 and PC2 were $42.90 \%$ and $22.97 \%$, respectively, which was sufficient to explain the variation of the sampling sites. All the samples (enhanced and control areas) were displayed in the plot. The distribution of different samples is likely affected by a variety of factors, such as spatial and temporal differences and environment parameters. As shown in Figure 7, the samples from the same period showed tighter clustering, whereas the samples from different areas were distributed relatively more widely. Moreover, the samples were primarily separated by PC1. The samples of the control area were placed on the positive side of PC1, whereas those of the enhanced area were scattered on the negative side of PC1. Deviating from our previous study in the enclosure system in the Zhoucun Reservoir, microbial communities were not clearly separated between the enhanced and control areas 
in this field experiment, and the influence of WLAs in the control area (although $2 \mathrm{~km}$ far away) might be the possible reason for this effect.

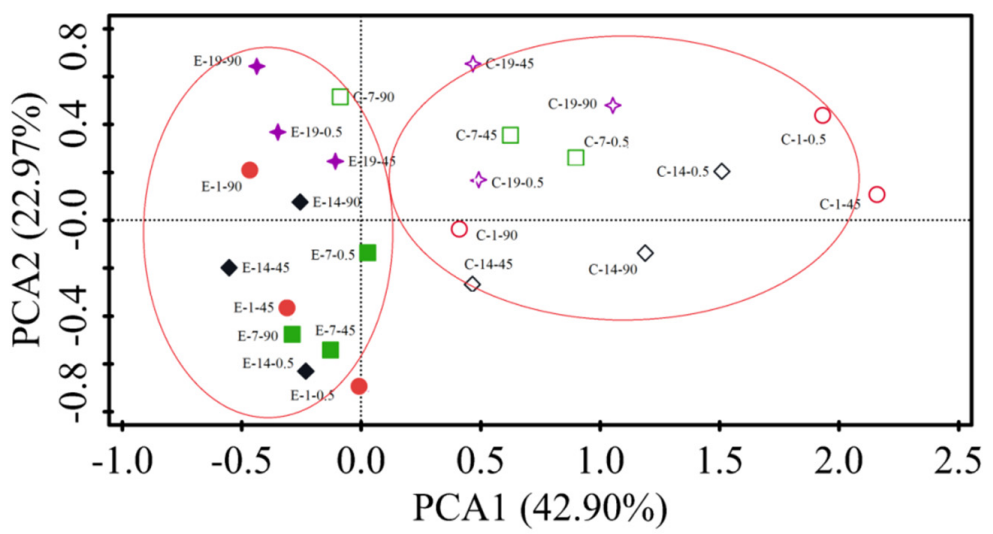

Figure 7. Principal component analysis (PCA) of water samples in the enhanced and control areas.

\subsection{Relationship of Microbial Community and Environmental Variables}

Multiple statistical analyses (RDA) were used to determine the relationship between the water quality and the bacterial community. The different bacterial communities present in the enhanced and control water samples were well discriminated at the gene level (Figure 5). The results in Figure 8 showed than the first two RDA dimensions with 12 parameters (VIF $<30$, except $\mathrm{TN}=46$ ) explained $35.23 \%$ of the microbial community variation $(\mathrm{F}=1.0, p=0.502)$ and the accumulated contribution ratios of RDA1 and RDA2 achieved $28.77 \%$ and $9.27 \%$, respectively. The water samples were separated by RDA2 (samples of the enhanced area were located in the positive values of RDA2, whereas those of the enhanced area were scattered on the negative values of RDA2). Meanwhile, the parameters including the physical environment factors (CHl-a, pH, T, ORP, and DO), chemical parameters (TOC, $\mathrm{TN}$, and TP), and the biological parameters (AD and denitrification functional genes) significantly influenced the microbial community composition. This was consistent with the operation of WLAs in the Jinpen reservoir ecosystem. It is clear that different sampling areas exhibited different bacterial communities. Thus, nitrogen removal by in situ enhancement of oxygen and indigenous aerobic denitrification bacteria using WLAs in the Jinpen reservoir was effective. However, the mechanism of nitrogen removal was not clear, and therefore, further exploration involving denitrifying enzymes, denitrification activities, and nitrogen metabolic genes (hao A, amoA, nosZ, nirK, and nirS) needs to be carried out in the future.

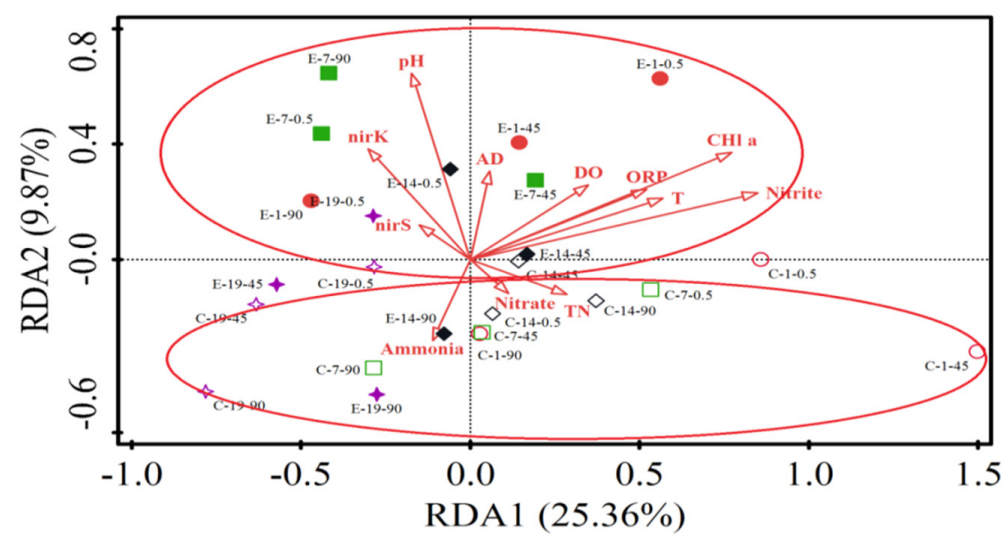

Figure 8. Redundancy analysis of water bacterial communities in the enhanced and control areas. 


\section{Conclusions}

Field tests of nitrogen removal were performed through operation of WLAs. In the enhanced area, nitrogen removal rate reached $29.1 \pm 0.8 \%$. Microbial carbon metabolism activity and carbon source utilization were improved compared to those in the control area. Aerobic denitrifier densities and denitrifying gene (nirK and nirS) copies were also increased by the operation of WLAs. The number of aerobic denitrifiers was increased by 2-5 times and nirS copy number in the enhanced area increased by $0.24-0.63$ times via the in situ operation. Miseq high-throughput sequencing indicated that denitrifying bacteria percentage was higher in the enhanced area, for example, in the enhanced area, the percentage of Acidovorax increased by 15 times from less than $0.01 \%$ (15 October) to $0.15 \%$ (2 November). In conclusion, WLAs can be used to improve water quality especially through nitrogen removal by the active indigenous aerobic denitrifiers.

Supplementary Materials: The following are available online at http:/ www.mdpi.com/2073-4441/10/8/1051/ s1.

Author Contributions: T.H. conceived the idea. Z.Z. designed the experiments and performed the experiments. Y.L., W.G., Y.L., Y.D., F.Z., S.Z., and W.M. analyzed the data and wrote the manuscript.

Funding: This research was funded by National Natural Science Foundation of China, grant number 51478378 and 50830303.

Acknowledgments: This study was supported by the National Natural Science Foundation of China (nos. 51478378 and 50830303). The authors would like to express their gratitude to the agencies involved and the study participants.

Conflicts of Interest: The authors declare no conflict of interest.

\section{References}

1. Fenech, C.; Rock, L. The potential for a suite of isotope and chemical markers to differentiate sources of nitrate contamination: A review. Water Res. 2012, 46, 2023-2041. [CrossRef] [PubMed]

2. Huang, T.; Lin, G. Nitrogen-removal efficiency of a novel aerobic denitrifying bacterium, Pseudomonas stutzeri strain ZF31, isolated from a drinking-water reservoir. Bioresour. Technol. 2015, 196, 209-216. [CrossRef] [PubMed]

3. Song, Z.F.; Yang, X.L. Isolation and characterization of an aerobic denitrifying Bacillus sp. YX-6 from shrimp culture ponds. Aquaculture 2011, 319, 188-193. [CrossRef]

4. Naeem, A. Enhanced biological nutrient removal by the alliance of a heterotrophic nitrifying strain with a nitrogen removing ecosystem. J. Environ. Sci. 2008, 20, 216-223.

5. Patureau, D.; Helloin, E. Combined phosphate and nitrogen removal in a sequencing batch reactor using the aerobic denitrifier, Microvirgula aerodenitrificans. Water Res. 2001, 35, 189-197. [CrossRef]

6. Qian, C.; Ni, J. Bioaugmentation treatment of municipal wastewater with heterotrophic-aerobic nitrogen removal bacteria in a pilot-scale SBR. Bioresour. Technol. 2015, 183, 25-32. [CrossRef]

7. Robertson, L.A.; Kuenen, J.G. Thiosphaera pantotropha gen. nov. sp. nov., a Facultatively Anaerobic, Facultatively Autotrophic Sulphur Bacterium. Microbiology 1983, 129, 2847-2855. [CrossRef]

8. Zhou, S.; Huang, T. Nitrogen removal characteristics of indigenous aerobic denitrifiers and changes in the microbial community of a reservoir enclosure system via in situ oxygen enhancement using water lifting and aeration technology. Bioresour. Technol. 2016, 214, 63-73. [CrossRef] [PubMed]

9. Yao, S.; Ni, J. Enrichment and characterization of a bacteria consortium capable of heterotrophic nitrification and aerobic denitrification at low temperature. Bioresour. Technol. 2013, 127, 151-157. [CrossRef] [PubMed]

10. Carter, J.P.; Hsaio, Y.H. Soil and sediment bacteria capable of aerobic nitrate respiration. Appl. Environ. Microbiol. 1995, 61, 2852-2858. [PubMed]

11. Joo, H.S.; Hirai, M. Piggery wastewater treatment using Alcaligenes faecalis strain No. 4 with heterotrophic nitrification and aerobic denitrification. Water Res. 2006, 40, 3029-3036. [CrossRef] [PubMed]

12. Guo, L.; Chen, Q. Application potential of a newly isolated indigenous aerobic denitrifier for nitrate and ammonium removal of eutrophic lake water. Bioresour. Technol. 2013, 142C, 45-51. [CrossRef] [PubMed] 
13. Patureau, D.; Godon, J.J. Microvirgula aerodenitrificans gen. nov., sp. nov., a new gram-negative bacterium exhibiting co-respiration of oxygen and nitrogen oxides up to oxygen-saturated conditions. Int. J. Syst. Bacteriol. 1998, 48 Pt 3, 775-782. [CrossRef] [PubMed]

14. Zhang, J.; Wu, P. Heterotrophic nitrification and aerobic denitrification by the bacterium Pseudomonas stutzeri YZN-001. Bioresour. Technol. 2011, 102, 9866-9869. [CrossRef] [PubMed]

15. Zhang, Q.L.; Liu, Y. The characteristics of a novel heterotrophic nitrification-aerobic denitrification bacterium, Bacillus methylotrophicus strain L7. Bioresour. Technol. 2012, 108, 35-44. [CrossRef] [PubMed]

16. Gao, H.; Schreiber, F. Aerobic denitrification in permeable Wadden Sea sediments. ISME J. 2011, 5, 417-426. [CrossRef]

17. Coban, O.; Kuschk, P. Nitrogen transforming community in a horizontal subsurface-flow constructed wetland. Water Res. 2015, 74, 203-212. [CrossRef] [PubMed]

18. Chai, B.; Huang, T. A new method of inhibiting pollutant release from source water reservoir sediment by adding chemical stabilization agents combined with water-lifting aerator. J. Environ. Sci. 2011, 23, 1977-1982. [CrossRef]

19. Gantzer, P.A.; Bryant, L.D. Controlling soluble iron and manganese in a water-supply reservoir using hypolimnetic oxygenation. Water Res. 2009, 43, 1285-1294. [CrossRef] [PubMed]

20. Zhou, Z.Z.; Huang, T.L. Impacts of water quality variation and rainfall runoff on Jinpen Reservoir, in Northwest China. Water Sci. Eng. 2015, 8, 301-308. [CrossRef]

21. Gao, H.; Schreiber, F.; Collins, G.; Jensen, M.M.; Lavik, G.; Kuypers, M.M.M. Aerobic Denitrification in Permeable Intertidal Sediments from the Wadden Sea; EGU General Assembly: Vienna, Austria, 2009.

22. Huang, T.; Xuan, L. Effects of storm runoff on the thermal regime and water quality of a deep, stratified reservoir in a temperate monsoon zone, in Northwest China. Sci. Total Environ. 2014, 485, 820-827. [CrossRef] [PubMed]

23. Zhou, S.; Huang, T. Nitrogen removal characteristics of enhanced in situ indigenous aerobic denitrification bacteria for micro-polluted reservoir source water. Bioresour. Technol. 2015, 201, 195-207. [CrossRef] [PubMed]

24. Herbert, R.B.; Winbjörk, H. Nitrogen removal and spatial distribution ofdenitrifier and anammox communities in a bioreactor for mine drainage treatment. Water Res. 2014, 66, 350-360. [CrossRef] [PubMed]

25. Ligi, T.; Truu, M. Effects of soil chemical characteristics and water regime on denitrification genes (nirS, nirK, and nosZ) abundances in a created riverine wetland complex. Ecol. Eng. 2013, 72, 47-55. [CrossRef]

26. Wang, L.; Zheng, B. Diversity of bacterial community and detection of nirS- and nirK-encoding denitrifying bacteria in sandy intertidal sediments along Laizhou Bay of Bohai Sea, China. Mar. Pollut. Bull. 2014, 1, 215-223. [CrossRef] [PubMed]

27. Zeng, W.; Zhang, J. Denitrifying phosphorus removal from municipal wastewater and dynamics of "Candidatus Accumulibacter" and denitrifying bacteria based on genes of ppk1, narG, nirS and nirK. Bioresour. Technol. 2016, 207, 322-331. [CrossRef] [PubMed]

28. Luo, J.; Liang, H. Microbial community structures in a closed raw water distribution system biofilm as revealed by 454-pyrosequencing analysis and the effect of microbial biofilm communities on raw water quality. Bioresour. Technol. 2013, 148, 189-195. [CrossRef] [PubMed]

29. Yan, Q.; Bi, Y. Impacts of the Three Gorges Dam on microbial structure and potential function. Sci. Rep. 2015, 5, 8605. [CrossRef] [PubMed]

(C) 2018 by the authors. Licensee MDPI, Basel, Switzerland. This article is an open access article distributed under the terms and conditions of the Creative Commons Attribution (CC BY) license (http:/ / creativecommons.org/licenses/by/4.0/). 